\title{
Optimizing Bariatric Surgery outcomes: the impact of preoperative elevated hemoglobin A1c levels on composite perioperative outcome measures
}

\author{
Alexander Hart ${ }^{1} \cdot$ Paolo Goffredo ${ }^{2}$ - Rory Carroll ${ }^{2} \cdot$ Ryan Lehmann $^{2} \cdot$ Peter Nau $^{2} \cdot$ Jessica Smith $^{2} \cdot$ Sajida Ahad $^{2}$. \\ Wei Bao ${ }^{3} \cdot$ Imran Hassan ${ }^{2}$
}

Received: 7 April 2020 / Accepted: 5 August 2020 / Published online: 12 August 2020

(c) Springer Science+Business Media, LLC, part of Springer Nature 2020

\begin{abstract}
Introduction The use of bariatric surgery in the management of obesity and its related morbidity has significantly increased in the US over the past decade. There is a lack of data on the impact of optimal preoperative glycemic control on the morbidity and mortality following bariatric surgery. The aim of this study was to analyze the impact of hemoglobin (Hb) A1c $>7$ on outcomes among patients undergoing Roux-en-Y gastric bypass (RYGB) or sleeve gastrectomy (SG).

Methods Data were extracted from the Metabolic and Bariatric Surgery Accreditation and Quality Improvement Program (2017) and limited to patients undergoing an elective laparoscopic RYGB or SG. Multivariable logistic regression was conducted to adjust for other preoperative variables.

Results A total number of 31,060 (69.3\%) patients underwent SG, while 13,754 (30.7\%) received RYGB. Patients who were older, male, non-Hispanic, smokers, and those with a higher American Society of Anesthesiologist Classification (ASA) score were more likely to have elevated HbA1c levels. Compared to individuals with normal HbA1c levels, patients with elevated levels had no significant difference in mortality $(p=0.902)$ but did have a difference in composite morbidity and mortality $(p<0.001)$. On multivariable analysis, elevated HbA1c, older age, increasing body mass index (BMI), elevated creatinine, longer operations, African American race, receiving RYGB, and having a trainee as surgical assistant were found to increase the odds of having an adverse outcome. No significant difference was found within smoking status, sex, ASA Classification, robotic vs laparoscopic, or if a second attending surgeon was assisting.

Conclusions $\mathrm{HbA} 1 \mathrm{c}$ levels and presence of trainees in the OR are modifiable preoperative risk factors for adverse events following bariatric surgery. Improving preoperative glycemic control may be an effective and achievable quality improvement measure.
\end{abstract}

Keywords HbA1c $\cdot$ Bariatric surgery $\cdot$ MBSAQIP $\cdot$ Outcomes $\cdot$ Glycemic control

Bariatric surgery has become increasingly utilized over the past decade as a safe and efficacious way to treat morbid

Alexander Hart and Paolo Goffredo have contributed equally to this work.

Imran Hassan

imran-hassan@uiowa.edu

1 Carver College of Medicine, University of Iowa, Iowa City, USA

2 Department of Surgery, University of Iowa Hospitals and Clinics, Iowa City, USA

3 Department of Epidemiology, University of Iowa, 200 Hawkins Drive, 1516 JCP, Iowa City, IA 52242, USA obesity and related conditions [1-4]. The indications for bariatric procedures include a Body Mass Index (BMI) $>40 \mathrm{~kg} / \mathrm{m}^{2}$, or having a BMI $>35 \mathrm{~kg} / \mathrm{m}^{2}$ with an obesityrelated comorbidity, including diabetes. Overall, $\sim 25 \%$ of morbidly obese patients will develop diabetes compared to $8.9 \%$ of the general population [5]. As a consequence, the obese subpopulation has an increased prevalence of elevated hemoglobin ( $\mathrm{Hb})$ A1c values [6-16].

Higher preoperative HbA1c levels are known to increase postoperative morbidity in a variety of surgical patient cohorts $[17,18]$. Aminian et al. developed a validated risk calculator tool utilizing a cohort of 659 patients from a single institution, where controlled preoperative $\mathrm{HbA} 1 \mathrm{c}$ was found to be a significant predictor of postoperative glycemic 
control [18]. This association between preoperative $\mathrm{HbA} 1 \mathrm{c}$ and postoperative glycemic control was also noted in a retrospective chart review of 468 bariatric surgery patient by Perna et al. [19] This study found elevated preoperative $\mathrm{HbAlc}$ to be associated with lower rates of diabetic remissions and weight loss. However, there is a scarcity of data on the impact of achieving good preoperative glycemic control on postoperative outcomes following bariatric surgery.

The current study aimed to analyze the association between preoperative $\mathrm{HbA} 1 \mathrm{c}$ levels and 30 day postoperative complications following bariatric surgery utilizing the Metabolic and Bariatric Surgery Accreditation and Quality Improvement Database. We hypothesized that elevated preoperative HbA1c levels $(>7)$ prior to bariatric surgery would be associated with worse postoperative outcomes.

\section{Materials and methods}

\section{Data source}

The Metabolic and Bariatric Surgery Accreditation and Quality Improvement Program Participant Use Data File (MBSAQIP PUF) was analyzed for the year 2017. This data file is Health Insurance Portability and Accountability Act Compliant covering 780 accredited bariatric surgery programs in the United States and Canada, and accounts for $94 \%$ of all bariatric surgeries in these countries. Data entry is performed by trained metabolic and bariatric surgical clinical reviewers via patient medical record review [20].

This study included all patients with documented preoperative HbA1c levels who underwent a standard laparoscopic or robotic Sleeve Gastrectomy (SG) or Roux-en-Y Bypass (RYGB) (Current Procedural Terminology codes 43775, 43644, and 43645). Sixty-six percent of the patients did not have a recorded preoperative $\mathrm{HbA} 1 \mathrm{c}$ level and were thus excluded from the analyses. Patients who had emergent, revision, open, or converted to open surgeries were excluded. Patients were also excluded if they had a history of previous midgut surgery or if they had secondary Current Procedural Terminology (CPT) codes associated with the treatment of comorbid conditions which would affect postoperative outcomes. Hemoglobin A1c levels $>7$ were defined as elevated. All patients had A1c levels checked prior to the surgical intervention.

\section{Outcomes and statistical analysis}

Complication data was collected from the MBSAQIP. This study utilizes a composite Death and Serious Morbidity outcome, which included 30-day mortality, ventilator requirement after $48 \mathrm{~h}$, an unplanned intubation, pneumonia, superficial surgical site infection, deep surgical site infection, organ space surgical site infection, pulmonary embolism, a reintervention within 30 days, myocardial infarction, sepsis, septic shock, cerebrovascular accident, cardiac arrest requiring cardio pulmonary resuscitation, progressive renal insufficiency, or vein thrombosis requiring treatment [21-23]. The composite outcome represented the summation of the counts of all listed adverse events. This decision was driven by the relatively low number of each individual complication.

Univariately continuous variables were compared using 2 -sided t-tests, and categorical variables were compared using chi-squared analysis. Multivariate logistic regression was conducted utilizing the composite outcome member. All tests were two sided and a $p$ value $<0.05$ was set for significance. $P$ values with $>4$ decimals were rounded up to $<0.001$. This work was deemed to be IRB exempt and did not qualify as human subject research. Analyses were conducted in SAS version 9.4 (SAS Institute, Cary, NC) 8.3.5.

\section{Results}

A total of 44,814 patients met inclusion criteria: $69.3 \%$ patients underwent SG, while $30.7 \%$ had RYGB. The cohort included primarily females (77.6\%) and Caucasians (72.6\%). Mean BMI was $45.6 \mathrm{~kg} / \mathrm{m}^{2}$.

The mean age in the elevated $\mathrm{HbA} 1 \mathrm{c}$ cohort was 47.7 years as compared to 43.6 years in the normal level population (Table 1). Gender differed significantly between the two groups with the elevated group being having a higher proportion of females compared to the normal group (71.1\% vs $79.6 \%, p<0.001)$. Also, positive smoking status was significantly higher in the elevated $\mathrm{HbA} 1 \mathrm{c}$ group being $8.7 \%$ of the cohort versus $8.0 \%$ in the normal group $(p=0.032)$. Additionally, mean BMI was lower in the elevated HbA1c group at $\left(45.0 \mathrm{~kg} / \mathrm{m}^{2}\right.$ vs $\left.45.8 \mathrm{~kg} / \mathrm{m}^{2}, p<0.001\right)$. Patients in the elevated $\mathrm{HbA1c}$ group underwent SG less frequently than the normal cohort $(61.7 \%$ vs $71.7 \%, p<0.001)$. The elevated $\mathrm{HbA} 1 \mathrm{c}$ group had a higher proportion of patients with $\mathrm{ASA} \geq 3$ as compared to the normal HbA1c group ( $85.8 \%$ vs $78.2 \%, p<0.001)$.

In univariate analysis, postoperative outcomes of patients with elevated $\mathrm{HbA} 1 \mathrm{c}$ levels were compared to those of the normal HbA1c group (Table 2). Although there was no difference in mortality, significantly higher rates of composite morbidity and mortality were observed in the elevated HbA1c group $(p<0.001)$.

On multivariable analysis, elevated $\mathrm{HbA} 1 \mathrm{c}$ was found to have significantly increased odds of having an adverse postoperative outcome (odds ratio $=1.2,95 \%$ CI 1.03-1.37). Older age, BMI, elevated creatinine, longer operations, African American race, and undergoing a RYGB were all independently associated with higher postoperative morbidity rates (all $p<0.001$ ). As 
Table 1 Preoperative univariate comparison between patients with elevated and non-elevated $\mathrm{HbA} 1 \mathrm{c}$ levels

\begin{tabular}{|c|c|c|c|}
\hline Variables & $\begin{array}{l}\mathrm{A} 1 \mathrm{c}>7 \\
N=10,641, \%\end{array}$ & $\begin{array}{l}\mathrm{A} 1 \mathrm{c} \leq 7 \\
N=34,173, \%\end{array}$ & $p$ value \\
\hline Female gender & 71.1 & 79.6 & $<.001$ \\
\hline Race & & & $<.001$ \\
\hline Black & 18.1 & 17.2 & \\
\hline Other & 8.3 & 10.6 & \\
\hline White & 73.7 & 72.3 & \\
\hline Age $($ mean \pm SD) & $47.7 \pm 11.4$ & $43.6 \pm 11.9$ & $<.001$ \\
\hline $\mathrm{BMI}($ mean $\pm \mathrm{SD})$ & $45.0 \pm 7.9$ & $45.8 \pm 7.9$ & $<.001$ \\
\hline ASA Category $\geq 3$ & 85.8 & 78.2 & $<.001$ \\
\hline Smoker status & 8.7 & 8.0 & 0.032 \\
\hline Hematocrit $($ mean \pm SD) & $41.0 \pm 4.1$ & $40.8 \pm 3.9$ & 0.004 \\
\hline Creatinine (mean $\pm \mathrm{SD})$ & $0.9 \pm 0.8$ & $0.8 \pm 0.5$ & $<.001$ \\
\hline Surgery Performed & & & $<.001$ \\
\hline Roux-en-Y Gastric Bypass & 38.3 & 28.3 & \\
\hline Sleeve Gastrectomy & 61.7 & 71.7 & \\
\hline First Assist level & & & $<.001$ \\
\hline None & 13.2 & 12.8 & \\
\hline $\mathrm{PA} / \mathrm{NP} / \mathrm{RN}$ & 43.7 & 36.7 & \\
\hline Resident (PGY1-5+) & 16.8 & 19.4 & \\
\hline MIS Fellow & 9.3 & 11.3 & \\
\hline Attending-Other & 3.7 & 4.4 & \\
\hline $\begin{array}{l}\text { Attending-Bariatric } \\
\text { Surgeon }\end{array}$ & 13.4 & 15.5 & \\
\hline Approach & & & $<.001$ \\
\hline Robotic-Assisted & 7.5 & 8.4 & \\
\hline $\begin{array}{l}\text { Conventional Laparo- } \\
\text { scopic }\end{array}$ & 87.4 & 89.2 & \\
\hline Laparoscopic assisted & 5.1 & 2.4 & \\
\hline $\begin{array}{l}\text { Operative time, } \min \\
(\text { mean } \pm S D)\end{array}$ & $87.8 \pm 49.0$ & $83.2 \pm 46.4$ & $<.001$ \\
\hline Drain Placement & 15.5 & 17.3 & $<.001$ \\
\hline
\end{tabular}

compared to having a nurse practitioner or physician assistant as lead assistant, there was no increased rates of complications when the case was performed by two attending physicians. However, procedures for which there was no assistant, a resident, or a fellow as the lead assist all had significant increased odds ratios of 1.4 (95\% CI 1.13-1.68), 1.3 (95\% CI 1.06-1.52), and 1.4 (95\% CI 1.10-1.66), respectively (Fig. 1). In a subset analysis comparing non-trainee assistants vs residents and fellows, the former group had a significantly lower reoperation rate $(1.0 \%$ vs $1.4 \%, p=0.030)$ and decreased operating time $(75 \pm 43$ vs $102 \pm 51$ minutes, $p<0.001)$. No significant difference was found within smoking status, sex, ASA Classification, or robotic vs laparoscopic surgical approach.

\section{Discussion}

This study utilized a large nationally representative database to evaluate the impact of $\mathrm{HbA} 1 \mathrm{c}$ on short-term outcomes after bariatric surgery. Our data suggest a positive association between elevated $\mathrm{HbA} 1 \mathrm{c}$ levels and the odds of developing postoperative complications. Moreover, the presence of trainees in the OR and undergoing RYGB were independently associated with adverse outcomes.

Our findings support the hypothesis that elevated $\mathrm{HbA1c}$ levels are associated with adverse outcomes following bariatric surgery. This observation is in contrast with the conclusion of Rawlins et al. Those authors published a retrospective study of 342 patients undergoing a RYGB and found that elevated preoperative $\mathrm{HbA} 1 \mathrm{c}$ did not increase complication rates [24]. This difference may be explained by two main reasons: 1 . the sample size was much smaller so the study had lower statistical power; 2 . all 342 patients were treated with medications for glycemic control, which could lessen the effects of elevated $\mathrm{HbA1c}$ levels. Other fields have also identified preoperative $\mathrm{HbA} 1 \mathrm{c}$ as a risk factor for postoperative morbidity. In posterior thoracic and lumbar spinal surgery, Hikata et al. found elevated $\mathrm{HbA} 1 \mathrm{c}$ to be associated with increased rates of surgical site infection [25]. Gustafsson et al., in the field of colorectal surgery, found among 120 prospectively followed patients that elevated preoperative $\mathrm{HbA1c}$ was predictive of poor postoperative glycemic control and increased postoperative complication rates [26]. Additionally, Underwood et al. reported that elevated $\mathrm{HbA} 1 \mathrm{c}$ was associated with poor surgical outcomes, such as longer length of stay, following non cardiac procedures on diabetics [27]. Moreover, following coronary artery bypass grafting, an elevated $\mathrm{HbA} 1 \mathrm{c}$ level was identified to significantly increase the odds of mortality, myocardial infarction, and deep sternal wound infection [28]. Interestingly, being in an elevated ASA category did not increase the risk of postoperative complications in this study. Elevated $\mathrm{HbA} 1 \mathrm{c}$ is included in calculating ASA category, indicating that this measure alone could be a more valuable indicator of postoperative risk compared to the composite preoperative measure. Therefore, given the elective setting of bariatric surgery, efforts should be made to control preoperative hyperglycemia to decrease the rate of short-term complications.

It was found that having no assist, a surgical resident, or a minimally invasive surgical fellow was associated with worse outcomes, as compared to having any attending surgeon as the lead assist. This is consistent with a study utilizing MBSAQIP by Bonner et al., which showed that having a trainee surgeon as assistant was significantly associated with adverse postoperative outcomes in 
Table 2 Postoperative outcomes by elevated and non-elevated HbA1c levels

\begin{tabular}{lllr}
\hline Outcome & Alc $>7$ & Alc $\leq 7$ & $p$ value \\
& $N=10,641, \%$ & $N=34,173, \%$ & $<.001$ \\
\hline Composite morbidity/mortality & 2.8 & 2.1 & 0.902 \\
30-day mortality & 0.1 & 0.1 & 0.264 \\
On Ventilator $>48 \mathrm{~h}$ & 0 & 0 & $<.001$ \\
Unplanned Intubation & 0.3 & 0.1 & 0.384 \\
Intervention within 30 days & 1.2 & 1.1 & 0.011 \\
Pneumonia & 0 & 0 & 0.845 \\
Pulmonary embolism & 0.1 & 0.1 & 0.361 \\
Myocardial infarction & 0 & 0 & 0.295 \\
Cerebrovascular accident & 0.1 & 0 & 0.150 \\
Cardiac arrest requiring CPR & 0.1 & 0.1 & 0.376 \\
progressive renal insufficiency & 0.1 & 0.1 & 0.561 \\
Vein thrombosis requiring treatment & 0.1 & 0.2 & $<0.001$ \\
Superficial surgical site infection & 0.6 & 0.4 & 0.213 \\
Deep surgical site infection & 0.1 & 0 & 0.3534 \\
Organ space surgical site infection & 0.3 & 0.2 & $<0.001$ \\
Post-op Pneumonia & 0.3 & 0.1 & 0.026 \\
Post-op septic shock & 0.1 & 0.1 & 0.001 \\
Post-op Sepsis & 0.2 & 0.1 &
\end{tabular}

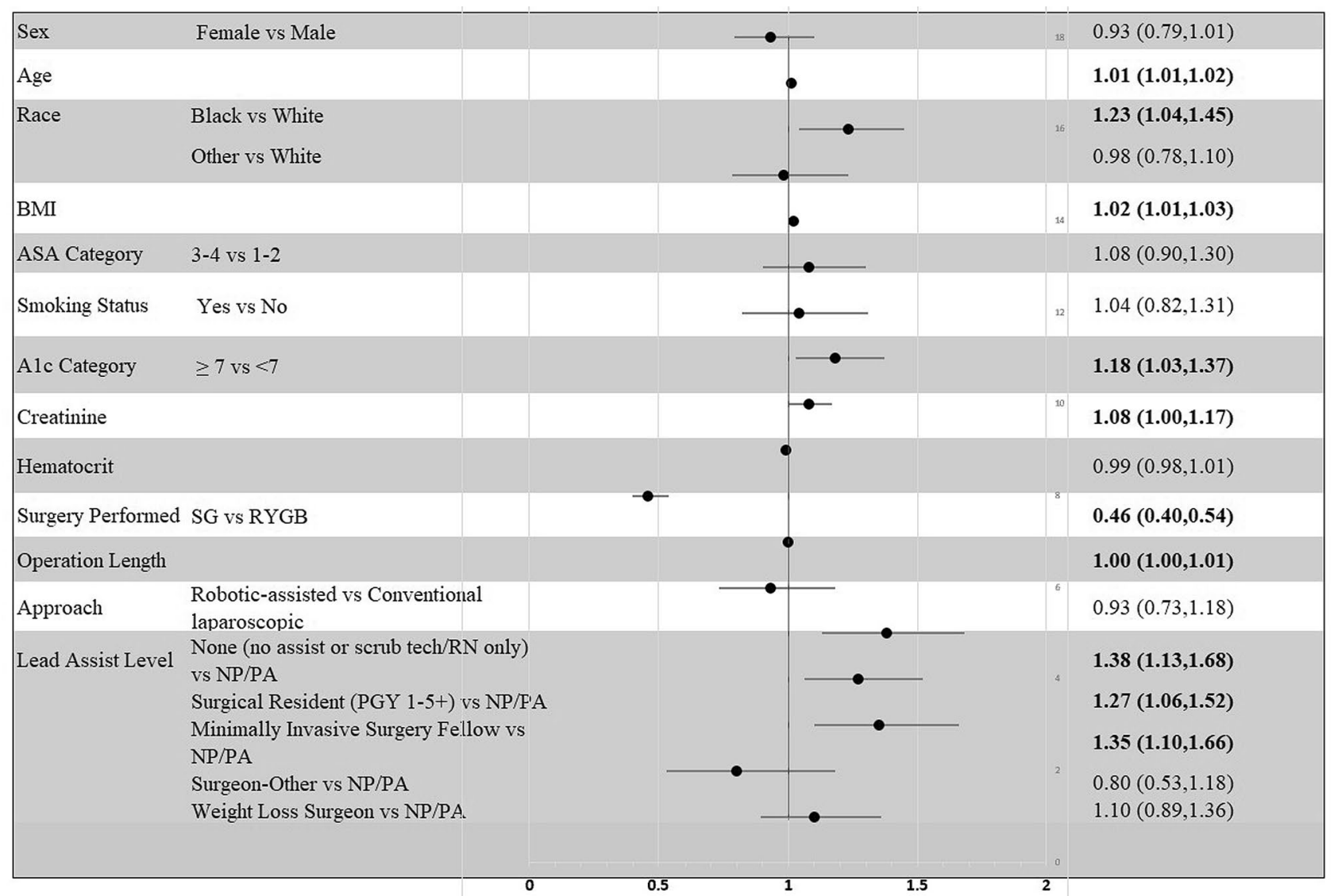

Fig. 1 Forest plot depicts the multivariate logistic regression with the composite morbidity and mortality outcome. Values on the right are reported as the odds ratio with the respective $95 \%$ confidence interval in parenthesis. Significant results are represented by bolding of the odds ratio and confidenc interval 
bariatric surgery [29]. In addition, Aminian et al. found in the standard NSQIP that fellows involved with Rouxen-Y bypass had increased odds of surgical complications and reoperation as compared to surgeries with no trainees involved [30]. Hsu et al. in a single institution study found similar results; lower assistant training levels were significantly associated with longer operative times and increased blood loss, as well as higher intraoperative complication and re-admission rates, intensive care unit admissions, or length of stay [31]. On the other hand, the results published by Oliak et al. and others showed that fellowship trained bariatric surgeons had shorter intraoperative time, lower rates of major complications, and decreased mortality [32-34]. These results indicate that further work should be done to implement new teaching models.in the training of bariatric surgeons to balance the complications of future versus current patients.

This study had several limitations, including those inherent to large datasets (ie coding errors). Although a composite outcome may limit the clinical interpretation of the results, this score was utilized for two primary reasons: (1) limited sample size of each individual outcome; and (2) wide range of systemic effects of elevated HbA1c levels. The goal was to capture this effect by combining a large variety of outcomes. However, due to differential frequencies of some adverse outcomes, there could be uneven representation of specific complications in the composite morbidity measure. Additionally, two thirds of the initial cohort were excluded due to missing $\mathrm{HbA1c}$ levels, which could have potentially introduced a bias in our analyses. This should be at least in part mitigated by the large sample size and the generally nationally representative nature of the MBSASQIP dataset. Another limitation was the ability to only measure information available in the database. Variables not included in the data set such as socio-economic or insurance status, current or previous medical management of diabetes, or center volume may have effects on surgical outcomes. Lastly, the MBSAQIP PUF only includes 30-day outcomes, therefore long-term outcomes could not be studied.

In conclusion, the current study identified high $\mathrm{HbA} 1 \mathrm{c}$ levels and presence of trainees in the OR as potentially modifiable preoperative risk factors for adverse events following bariatric surgery in a nationally representative cohort. Improving preoperative glycemic control prior to bariatric surgery may be a feasible goal, which could represent an important quality improvement measure. Presence of trainees in the operating room, on the other hand, poses a more difficult challenge to overcome. Further studies focusing on surgical education would be warranted to implement safe and effective training in the field of bariatric surgery.
Funding None.

\section{Compliance with ethical standards}

Disclosures Mr. Hart, Dr. Goffredo, Dr. Carroll, Dr. Lehmann, Dr. Nau, Dr. Smith, Dr. Ahad, Dr. Bao, and Dr. Hassan have no conflicts of interest or financial ties to disclose.

\section{References}

1. Lo Menzo E, Szomstein S, Rosenthal RJ (2015) Changing trends in bariatric surgery. Scand J Surg 104:18-23

2. Khorgami Z, Shoar S, Andalib A, Aminian A, Brethauer SA, Schauer PR (2017) Trends in utilization of bariatric surgery, 2010-2014: sleeve gastrectomy dominates. Surg Obes Relat Dis 13:774-778

3. Debs T, Petrucciani N, Kassir R, Iannelli A, Amor IB, Gugenheim $\mathrm{J}$ (2016) Trends of bariatric surgery in France during the last 10 years: analysis of 267,466 procedures from 2005-2014. Surg Obes Relat Dis 12:1602-1609

4. Johnson EE, Simpson AN, Harvey JB, Simpson KN (2016) Bariatric surgery implementation trends in the USA from 2002 to 2012. Implement Sci 11:21

5. Surgery for Diabetes (2020) American society for metabolic and bariatric surgery. https://asmbs.org/patients/surgery-for-diabetes. Accessed 1 April 2020

6. Qi L, Guo Y, Liu CQ, Huang ZP, Sheng Y, Zou DJ (2017) Effects of bariatric surgery on glycemic and lipid metabolism, surgical complication and quality of life in adolescents with obesity: a systematic review and meta-analysis. Surg Obes Relat Dis 13:2037-2055

7. Schauer PR, Bhatt DL, Kirwan JP, Wolski K, Aminian A, Brethauer SA, Navaneethan SD, Singh RP, Pothier CE, Nissen SE, Kashyap SR (2017) Bariatric surgery versus intensive medical therapy for diabetes - 5-year outcomes. N Engl J Med 376:641-651

8. Buchwald H, Estok R, Fahrbach K, Banel D, Jensen MD, Pories WJ, Bantle JP, Sledge I (2009) Weight and type 2 diabetes after bariatric surgery: systematic review and meta-analysis. Am J Med 122:248-256.e245

9. Ashrafian H, Harling L, Toma T, Athanasiou C, Nikiteas N, Efthimiou E, Darzi A, Athanasiou T (2016) Type 1 diabetes mellitus and bariatric surgery: a systematic review and meta-analysis. Obes Surg 26:1697-1704

10. Zeng T, Cai Y, Chen L (2017) The effectiveness of bariatric surgery for chinese obesity in 2 years: a meta-analysis and systematic review. J Invest Surg 30:332-341

11. Courcoulas AP, Christian NJ, Belle SH, Berk PD, Flum DR, Garcia L, Horlick M, Kalarchian MA, King WC, Mitchell JE, Patterson EJ, Pender JR, Pomp A, Pories WJ, Thirlby RC, Yanovski SZ, Wolfe BM (2013) Weight change and health outcomes at 3 years after bariatric surgery among individuals with severe obesity. JAMA 310:2416-2425

12. Galioto R, Alosco ML, Spitznagel MB, Strain G, Devlin M, Cohen R, Crosby RD, Mitchell JE, Gunstad J (2015) Glucose regulation and cognitive function after bariatric surgery. J Clin Exp Neuropsychol 37:402-413

13. Ribaric G, Buchwald JN, McGlennon TW (2014) Diabetes and weight in comparative studies of bariatric surgery vs conventional medical therapy: a systematic review and meta-analysis. Obes Surg 24:437-455 
14. Sultan S, Gupta D, Parikh M, Youn H, Kurian M, Fielding G, Ren-Fielding C (2010) Five-year outcomes of patients with type 2 diabetes who underwent laparoscopic adjustable gastric banding. Surg Obes Relat Dis 6:373-376

15. Nocca D, Guillaume F, Noel P, Picot MC, Aggarwal R, El Kamel M, Schaub R, de Seguin de Hons C, Renard E, Fabre JM (2011) Impact of laparoscopic sleeve gastrectomy and laparoscopic gastric bypass on $\mathrm{HbA} 1 \mathrm{c}$ blood level and pharmacological treatment of type 2 diabetes mellitus in severe or morbidly obese patients. Results of a multicenter prospective study at 1 year. Obes Surg 21:738-743

16. Abbatini F, Rizzello M, Casella G, Alessandri G, Capoccia D, Leonetti F, Basso N (2010) Long-term effects of laparoscopic sleeve gastrectomy, gastric bypass, and adjustable gastric banding on type 2 diabetes. Surg Endosc 24:1005-1010

17. van den Boom W, Schroeder RA, Manning MW, Setji TL, Fiestan GO, Dunson DB (2018) Effect of A1C and glucose on postoperative mortality in noncardiac and cardiac surgeries. Diabetes Care 41:782-788

18. Bock M, Johansson T, Fritsch G, Flamm M, Hansbauer B, Mann E, Sonnichsen A (2015) The impact of preoperative testing for blood glucose concentration and haemoglobin A1c on mortality, changes in management and complications in noncardiac elective surgery: a systematic review. Eur J Anaesthesiol 32:152-159

19. Perna M, Romagnuolo J, Morgan K, Byrne TK, Baker M (2012) Preoperative hemoglobin A1c and postoperative glucose control in outcomes after gastric bypass for obesity. Surg Obes Relat Dis 8:685-690

20. Telem DA, Dimick JB (2018) Practical guide to surgical data sets: metabolic and bariatric surgery accreditation and quality program (MBSAQIP). JAMA Surg 153:766-767

21. Haskins IN, Ju T, Whitlock AE, Rivas L, Amdur RL, Lin PP, Vaziri K (2018) Older age confers a higher risk of 30-day morbidity and mortality following laparoscopic bariatric surgery: an analysis of the metabolic and bariatric surgery quality improvement program. Obes Surg 28:2745-2752

22. Flum DR, Belle SH, King WC, Wahed AS, Berk P, Chapman W, Pories W, Courcoulas A, McCloskey C, Mitchell J, Patterson E, Pomp A, Staten MA, Yanovski SZ, Thirlby R, Wolfe B (2009) Perioperative safety in the longitudinal assessment of bariatric surgery. N Engl J Med 361:445-454

23. El Chaar M, Stoltzfus J, Gersin K, Thompson K (2019) A novel risk prediction model for 30-day severe adverse events and readmissions following bariatric surgery based on the MBSAQIP database. Surg Obes Relat Dis 15:1138-1145

24. Rawlins L, Rawlins MP, Brown CC, Schumacher DL (2013) Effect of elevated hemoglobin A1c in diabetic patients on complication rates after Roux-en-Y gastric bypass. Surg Obes Relat Dis 9:749-752

25. Hikata T, Iwanami A, Hosogane N, Watanabe K, Ishii K, Nakamura M, Toyama Y, Matsumoto M, Kamata M (2014) High preoperative hemoglobin A1c is a risk factor for surgical site infection after posterior thoracic and lumbar spinal instrumentation surgery. J Orthop Sci 19:223-228

26. Gustafsson UO, Thorell A, Soop M, Ljungqvist O, Nygren J (2009) Haemoglobin A1c as a predictor of postoperative hyperglycaemia and complications after major colorectal surgery. $\mathrm{Br} \mathrm{J}$ Surg 96:1358-1364

27. Underwood P, Askari R, Hurwitz S, Chamarthi B, Garg R (2014) Preoperative $\mathrm{A} 1 \mathrm{C}$ and clinical outcomes in patients with diabetes undergoing major noncardiac surgical procedures. Diabetes Care 37:611-616

28. Halkos ME, Puskas JD, Lattouf OM, Kilgo P, Kerendi F, Song HK, Guyton RA, Thourani VH (2008) Elevated preoperative hemoglobin A1c level is predictive of adverse events after coronary artery bypass surgery. J Thorac Cardiovasc Surg 136:631-640

29. Bonner G, Kalantar Motamedi SM, Mustafa RR, Abbas M, Khaitan L (2018) The educating enigma: Does training level impact postoperative outcome in bariatric surgery? Surgery 164:784-788

30. Aminian A, Chaudhry RM, Khorgami Z, Andalib A, Augustin T, Rodriguez J, Kroh M, Schauer PR, Brethauer SA (2016) A challenge between trainee education and patient safety: does fellow participation impact postoperative outcomes following bariatric surgery? Obes Surg 26:1999-2005

31. Hsu GP, Morton JM, Jin L, Safadi BY, Satterwhite TS, Curet MJ (2005) Laparoscopic Roux-en-Y gastric bypass: differences in outcome between attendings and assistants of different training backgrounds. Obes Surg 15:1104-1110

32. Sucandy I, Antanavicius G (2013) Impact of minimally invasive/ bariatric surgery fellowship on perioperative complications and outcomes in the first year of practice. N Am J Med Sci 5:419-421

33. Agrawal $S$ (2011) Impact of bariatric fellowship training on perioperative outcomes for laparoscopic Roux-en-Y gastric bypass in the first year as consultant surgeon. Obes Surg 21:1817-1821

34. Oliak D, Owens M, Schmidt HJ (2004) Impact of fellowship training on the learning curve for laparoscopic gastric bypass. Obes Surg 14:197-200

Publisher's Note Springer Nature remains neutral with regard to jurisdictional claims in published maps and institutional affiliations. 